IZA DP No. 7122

The Changing of the Guards:

Can Physicians Contain Social Insurance Costs?

Simen Markussen

Knut Røed

Ole Røgeberg

January 2013 


\title{
The Changing of the Guards: Can Physicians Contain Social Insurance Costs?
}

\author{
Simen Markussen \\ The Ragnar Frisch Centre for Economic Research \\ Knut Røed \\ The Ragnar Frisch Centre for Economic Research \\ and IZA \\ Ole Røgeberg \\ The Ragnar Frisch Centre for Economic Research
}

\author{
Discussion Paper No. 7122 \\ January 2013
}

IZA
P.O. Box 7240
53072 Bonn
Germany

Phone: +49-228-3894-0

Fax: +49-228-3894-180

E-mail: iza@iza.org

\begin{abstract}
Any opinions expressed here are those of the author(s) and not those of IZA. Research published in this series may include views on policy, but the institute itself takes no institutional policy positions. The IZA research network is committed to the IZA Guiding Principles of Research Integrity.

The Institute for the Study of Labor (IZA) in Bonn is a local and virtual international research center and a place of communication between science, politics and business. IZA is an independent nonprofit organization supported by Deutsche Post Foundation. The center is associated with the University of Bonn and offers a stimulating research environment through its international network, workshops and conferences, data service, project support, research visits and doctoral program. IZA engages in (i) original and internationally competitive research in all fields of labor economics, (ii) development of policy concepts, and (iii) dissemination of research results and concepts to the interested public.
\end{abstract}

IZA Discussion Papers often represent preliminary work and are circulated to encourage discussion. Citation of such a paper should account for its provisional character. A revised version may be available directly from the author. 


\section{ABSTRACT \\ The Changing of the Guards: Can Physicians Contain Social Insurance Costs?*}

Based on administrative data from Norway, we examine the extent to which family doctors influence their clients' propensity to claim sick pay and disability benefits. The analysis is based on exogenous shifts of family doctors occurring when physicians quit, retire, or for other reasons sell their patient lists to other doctors. Our key finding is that family doctors have significant influence on their clients' benefit claims. We conclude that it is possible for family doctors to contain social insurance costs to some extent, and that there is a significant variation across doctors in the way they do so.

JEL Classification: H55, I13

Keywords: $\quad$ sick pay, disability insurance, absence certification, gatekeepers

Corresponding author:

Knut Røed

The Ragnar Frisch Centre for Economic Research

Gaustadalléen 21

0349 Oslo

Norway

E-mail: knut.roed@frisch.uio.no

\footnotetext{
* This research has received financial support from the Norwegian Research Council through the program "Sickness, absence, work and health" (grant nos. 187924 and 201416). Thanks to seminar participants at Statistics Norway and at the Economics Department, University of Oslo, for valuable comments. Data made available by Statistics Norway have been essential.
} 


\section{Introduction}

Publicly mandated sick pay and disability insurance schemes are an important part of the social safety net in many countries. Given the relatively high replacement ratios in these schemes, they entail the risk of excessive use, and even outright shirking (frequently called «moral hazard» in the social insurance literature of economics). To counter this risk, sickness and disability claims typically need to be certified by a physician. Consequently, medical professionals have been given a rather prominent role in containing public spending. The decisions they make about persons' fitness for work determine how long they can remain detached from their workplaces and claim benefits. While there has been a trend across OECD countries to raise the powers of the benefit-granting institutions in relation to long-term disability benefit claims, sickness absence certificates continue to be provided by general practitioners (GPs) in virtually all countries; see OECD (2010, p. 139).

The GPs thus remain important gatekeepers of the welfare states' public purses. The rational behind this policy is that physicians can, better than anyone, verify the presence of illness and thus decide whether or not a person is eligible for sick pay or disability benefits. At the same time, these physicians operate in a competitive environment, where their profits depend on their ability to recruit clients. To the extent that access to sickness or disability benefits is desired by (potential) clients, the physicians' own economic interests may erode their gatekeeper role. So far, attempts to assess the efficacy of physicians-as-gatekeepers have been mainly theoretical (Scott, 2000; Brekke et.al, 2007; Dusheiko et.al, 2006). Focus has been on the information advantage physicians have over patients regarding the relationship between health 
status and treatment (e.g., Scott, 2000), the information advantage patients have over doctors regarding private health (e.g., Stone, 1986), or the tension in the physician’s role as both advocate of the patient and health-assessor on behalf of the insurance provider (e.g., Blomqvist, 1991). On the basis of a theoretical model and qualitative interview data from a sample of general practitioners, Carlsen and Nyborg (2009) argue that there are neither theoretical nor empirical grounds for expecting general practitioners to fulfill the role of effective gate-keeping, and conclude that «the gate is wide open».

On the empirical side, Wilkin (1992) identify a large variation between physicians in the frequency of referrals to specialist treatment, and Grytten and Sørensen (2003) identify a similarly large variation in their use of (expensive) laboratory tests. More related to the topic of the present paper, Markussen et.al (2011) report a large variation in physicians' tendency to certify sick-leave. A fundamental problem with empirically identifying the influence of physicians on their patients' behavior, however, is that patients are not allocated randomly to physicians; hence, differences in observed absence rates across physicians’ patient groups may reflect sorting as well as causality. In particular, patients demanding a (questionable) sickness certificate may seek out an accommodative («lenient») physician. While this problem can be reduced by controlling for observed patient characteristics, it is typically difficult to ascertain that no unobserved sorting problems remain. In the present paper, we address this problem by exploiting physician changes that arguably are exogenous with respect to the behavior and characteristics of each patient, namely events where whole client lists are sold from one doctor to another. 
Our empirical basis is administrative data from Norway that provide information about the identity of all citizens' family doctors, and also contain records on employment and physician-certified sick leaves and disability benefit claims. Norway is a particularly well suited country for investigating the role of physicians, since everyone in Norway has been assigned a GP who is their primary contact point with the public health care and sickness/disability insurance systems, regardless of whether they have actually consulted the doctor or not. In the main, these GPs are the ones responsible for certifying illness for workers. The system has the additional feature that when a GP moves to another job/district, retires or closes the practice for other reasons, the list of patients is sold to another GP and the patients are collectively moved to this new GP.

The main research question we seek to answer in the present paper is the following: Does a family doctor have a significant influence on the level of sickness absence and disability benefit claims in his/her group of patients? The more extreme variants of the gate-keeping-doesn't-work-and-may-even-be-impossible argument would predict that the level of benefit claims is independent of which physician the patient is referred to, and we would consequently not expect an exogenous shift of GP to cause changes in claim behavior. If, on the other hand, there are substantial and persistent differences between physicians in terms of their «strictness» or «leniency» which are not fully neutralized by «physician shopping», we would expect an exogenous shift of GP to entail noticeable changes.

Our paper is also motivated by a more methodological issue: If the family doctor has a direct effect on a worker's benefit claims, this would potentially imply that indicators for physician strictness can be used as exogenous instruments to answer 
questions about the causal effect of becoming a benefit claimant. This has been done by Markussen (2012), who investigated the impact of absenteeism on subsequent earnings growth, using the physician-strictness indicators reported by Markussen et al. (2011) as an instrumental variable. Similar identification strategies have also been used by Duggan (2005) who examined the impact of new/expensive antipsychotic drugs on subsequent health care spending, using psychiatrists’ propensity to prescribe expensive drugs as instrumental variable, and by French and Song (2009) and Maestas et al. (2011) who investigated the impact of disability insurance receipt on subsequent labor supply, using the health examiners' observed allowance rates as an instrumental variable. Our paper sheds light on the potential power of these empirical approaches by assessing the influence that gate keepers really have on these kinds of decisions when all individual factors are appropriately controlled for. In particular, we offer a reexamination of the physician-strictness indicators computed by Markussen et al. (2011) as our data to some extent encompass the same group of physicians.

The key finding of our paper is that family doctors really do have a significant impact on their patients' benefit claims. For example, by comparing patient groups who were subject to an exogenous shift of family doctor with similar groups who were not subject to such a shift, we find that the expected absolute change (positive or negative) in the groups' benefit claims over the next two years were $25 \%$ larger in the groups that were subject to a switch. We also find that «new» doctors certify significantly more benefits than «old» doctors, suggesting either that it is difficult to be a good gatekeeper for the welfare state when it comes to patients whom the doctor does not know very well, or that new family doctors are under stronger competitive pressure than established ones, and thus find it more costly to go against the patient's re- 
quests. Comparing our results to those reported by Markussen et al. (2011) for the same group of physicians, we find a large degree of concordance. Given the completely different identification strategies used, we interpret this as further evidence that there really are significant differences between physicians in the way they fulfill their gatekeeper role. Physicians do indeed have some powers to contain social insurance costs, but they use them to varying degrees.

\section{Institutional setting and data}

In Norway, workers receive 100 percent wage compensation from the first day of sickness absence and for up to one year (up to an income ceiling of approximately 500,000 NOK (2012)). A sick leave certificate issued by a physician is normally required already after three days of absence. ${ }^{1}$ Following exhaustion of sick pay entitlements, workers may apply for temporary or permanent disability benefits. ${ }^{2}$ The replacement ratio in these programs is typically around $66 \%$. Again, a certificate from the patient's physician is required, and, if in doubt, the social security administration may ask for second opinions from other specialists. On a typical working day, 6-7 \% of Norwegian employees are absent from work due to sickness, and almost $90 \%$ of these absences are certified by a physician. In addition, around $15 \%$ of the workingage population receives a temporary or permanent disability benefit.

Norway has, since May 2001, practiced a family (panel) doctor system, whereby each citizen is assigned a single GP who receives a capitation fee from the

\footnotetext{
${ }^{1}$ Some firms have agreed to accept self-reported sickness claims for up to eight days.

${ }^{2}$ We use the term «temporary disability benefit» to denote benefits claimed during periods of medical and/or vocational rehabilitation. Such periods may last for up to 3-4 years, after which a permanent disability benefit may be granted. Permanent disability benefits may also be granted just after sick pay exhaustion if it is obvious that rehabilitation attempts will fail.
} 
social security administration. Sickness absence and disability certificates can in principle be issued by any authorized physician, but it will normally be issued by the family doctor, except in emergency cases and when the patient is hospitalized or subject to intensive specialist treatment. Norwegian workers are free to choose their family doctor insofar as the desired doctor has vacant patient slots, but unless they make an active choice, they will be assigned a «default» GP, based on their residential address. When a physician retires or moves to a new job (or a new location), the whole patient list will be sold to a new GP, but - as we return to below - patients may of course self-select to other physicians at these occasions.

The data we use in the present paper are collected from Norwegian administrative registers made available to us by Statistics Norway. They cover the complete population during the period from May 2001 through December 2005, with individual level (encrypted) panel data information concerning patient-GP-linkages, employment spells, physician-certified absence spells, disability benefit claims, demographic information (gender, age, nationality), and educational attainment. We use these data to construct a monthly outcome measure indicating - for each person - whether a physician-certified benefit (sick pay, rehabilitation benefits, or disability benefits) was received in that month or not.

The population we are interested in consists of workers who are forced to change family doctor because their original GP sells the whole practice to a new doctor. In these cases, we can interpret the patient-GP split as exogenous with respect to each patient's behavior and characteristics. The basic idea behind our empirical approach is to examine the frequency of sick pay and disability benefit claims around the time of physician changes in order to assess whether there are changes in these 
frequencies that are attributable to the physician shifts. Since the frequency of sick pay and disability claims obviously changes over time for a number of reasons (cyclical and seasonal fluctuations, time-trends, ageing, pure randomness), we need a control group of physicians with stable patient lists to represent the counterfactual case of remaining with the same GP. Now, a potential problem with this approach is that if some of the patients subject to a physician-shift anticipate the shift, they may start looking for a new GP even before the shift occurs; implying that the list eventually sold to a new doctor contains a selected sub-group of original list members. Moreover, it is probable that patients and physicians behave differently when they know that the relationship between them is going to end in the near future. To address these problems, we will interpret the client-list that applied 12 months before the actual shift as defining the «treated» population. We also disregard any subsequent physician shifts, since these may occur as an endogenous response to the behavior of the new physician. This implies that we use a completely balanced panel to study the frequency of benefit claims before and after the time of the physician shifts. As we return to below, this creates a sort of attenuation bias when we evaluate the influence of the new physician relative to the old one. We also restrict attention to persons who were employed 12 months prior to the shift, since employment is a precondition for sick pay and since recent employment typically constitute the basis for disability benefit eligibility.

Formally, we denote the set of patients moving collectively from physician $m$ to physician $n$ at time $s$ and observed in month $t$ by $\left\{\mathbf{P}_{s}\right\}_{t}^{m, n} .{ }^{3}$ We can refer to $m$ as the

\footnotetext{
${ }^{3}$ Note that physician shifts in Norway always occur at the border between two months.
} 
patient-supplying GP, and $n$ as the patient-receiving GP. The treatment sample is constructed by identifying all GP induced switches that involved a group of 300 or more patients $\left(\mathrm{P}_{\mathrm{s}} \geq 300\right)$, and took place in the period from May 2002 through December 2003. The latter limitation is imposed to ensure that we can follow the list-members behavior from one year before till two years after the shift. All the patients that the physician had exactly one year before shift, and who were employed at that point are included in the sample as treated. Figure 1, panel a) shows the frequency of exogenous physician shifts included in our analysis by calendar month. Although the shifts are spread out over time, there is a disproportionally large fraction of them occurring before/after the summer and Christmas holidays. Panel b) shows the size distribution of the employed list-members actually included in our analysis Most of the shifts involve around 150-400 employees. ${ }^{4}$ For each treated patient group, we select a corresponding (employed) control patient group belonging to a physician who did not quit. Formally, we denote the control group as $\left\{\mathbf{P}_{s}\right\}_{t}^{m, m}$, where $s$ now refers to the timing of the physician shift occurring in the treatment group for which the group is a control. Hence, we may think of the control groups as experiencing «placebo» physician shifts (with $n=m$ ) at exactly the same time as the treatment groups. Control groups are selected to ensure similar sizes as the treatment groups (in order to ascertain a similar level of random variation in outcomes over time), and also similar past absence patterns. More specifically, we define the set of potential control groups for treatment group $m$ as all patient groups who were not subject to an exogenous physician change during our observation window and who’s employed population had absence rates in

\footnotetext{
${ }^{4}$ Note that the minimum requirement of 300 patients was imposed on the total number of listmembers, including children, retirees, and other non-employed persons.
} 
both the two six month periods prior to the time of matching that did not deviate more than half a percentage point from the treatment group. From this set, we pick the GP whose employed client list size was closest to the treated client group's list at the time of matching

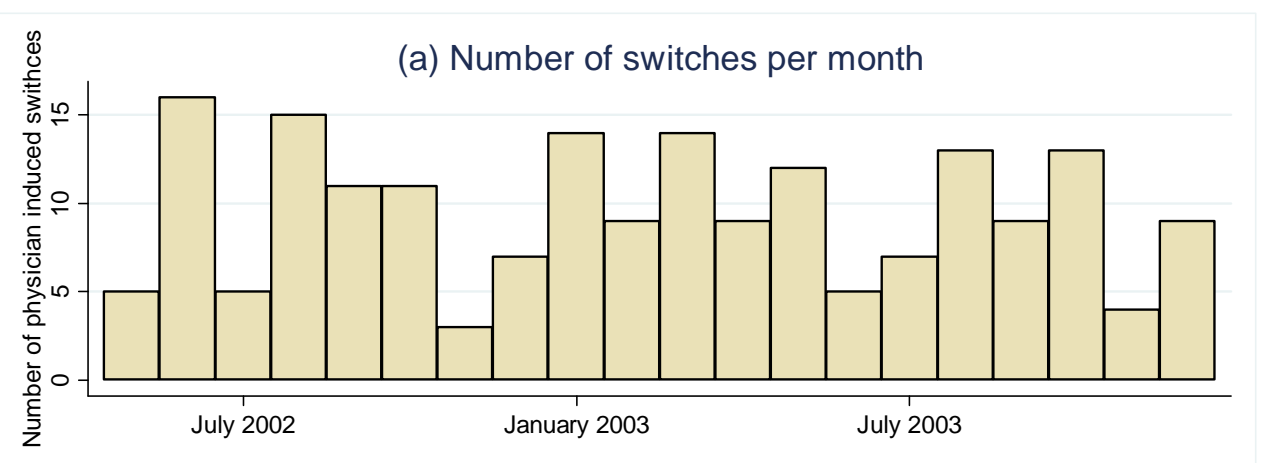

(b) Size-distribution of the switches

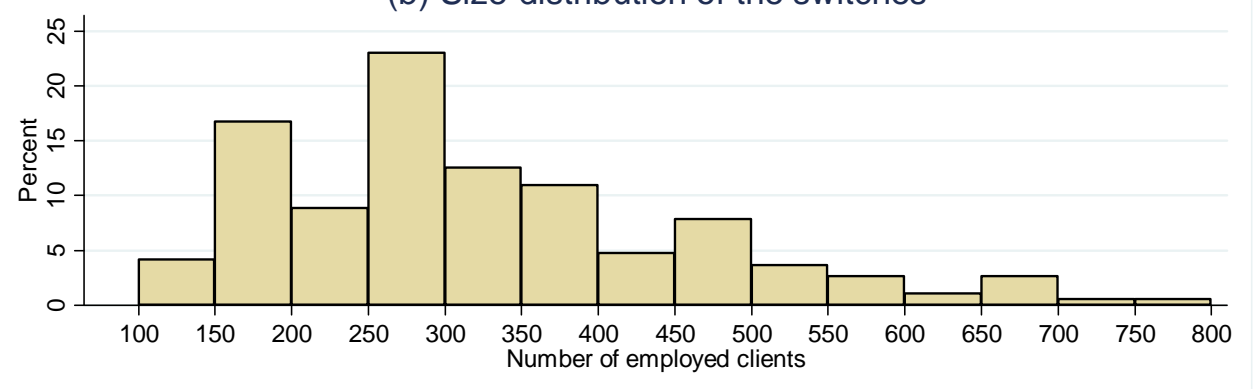

Figure 1: The number of exogenous switches, their timing and the number of employed patients involved

Note: The months indicated in panel a) are the last months before the shift (e.g., a July-bar indicates the shifts occurring between July and August).

Table 1 provides some summary statistics for the resulting treated and nontreated workers. In total, we have data for 191 treatment groups with an average number of employed clients of 324. The control groups are of almost exactly the same sizes (326 on average), and have a very similar composition of their clients. 


\begin{tabular}{lcc}
\hline Table 1. Descriptive statistics (standard deviations in parentheses) & $\begin{array}{c}\text { Control group } \\
\text { Treatment group }\end{array}$ \\
\hline Number of physicians & 191 & 191 \\
Number of persons & 62243 & 61814 \\
$\quad$ Age (years) & 41.7 & 40.9 \\
$\quad$ Females (\%) & $(10.9)$ & $(10.9)$ \\
$\quad 45.3$ & 43.4 \\
Years of schooling & 13.3 & 13.1 \\
Fraction receiving short and long-term disability benefits & $(2.7)$ & $(2.6)$ \\
12 months before physician switch & & \\
1 month before physician switch & 6.2 & 6.1 \\
1 year after physician switch & 7.6 & 8.1 \\
2 years after physician switch & 9.2 & 9.4 \\
& 9.8 & 9.9 \\
\hline
\end{tabular}

As pointed out above, some patients in any group $\left\{\mathbf{P}_{s}\right\}_{t}^{m, n}$ may be exposed to GPs other than $m$ and $n$, since individuals are free to choose their GP at any time. The sampling scheme ensures that we follow all patients associated with a physician $m$ from one year before the exogenous (genuine or placebo) shift, and interpret them as treated by this particular shift regardless of any subsequent transitions to other doctors. This implies that the estimated effects of the shifts can be given a sort of intention-to-treat interpretation. What we can hope to identify from our analysis is thus not the impacts of moving from physician $m$ to physician $n$, but rather the impact of being exogenously split from physician $m$ and offered physician $n$ as a new default choice. The impacts will include any effects that the exogenous shift has on subsequent patient-initiated shifts.

Figure 2 illustrates the degree of «non-compliance» for the treatment and the control groups. Not surprisingly, patient-initiated switching is much more common in the treated patient groups - especially after the exogenous switch. This illustrates the point that a new doctor may be under stronger competitive pressure than an established one. 


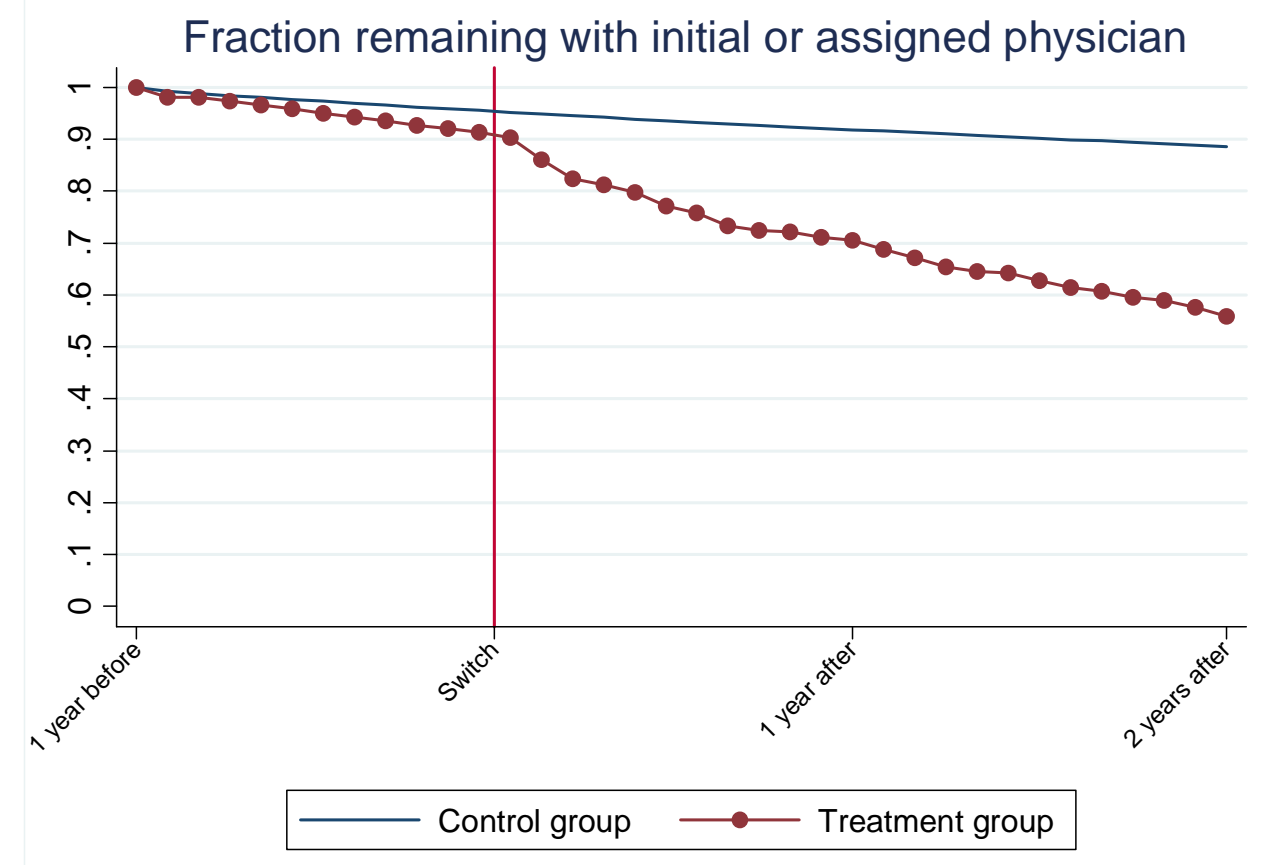

Figure 2. Fraction of initial patient population (12 months before the shift) that stays with initial or new assigned physician.

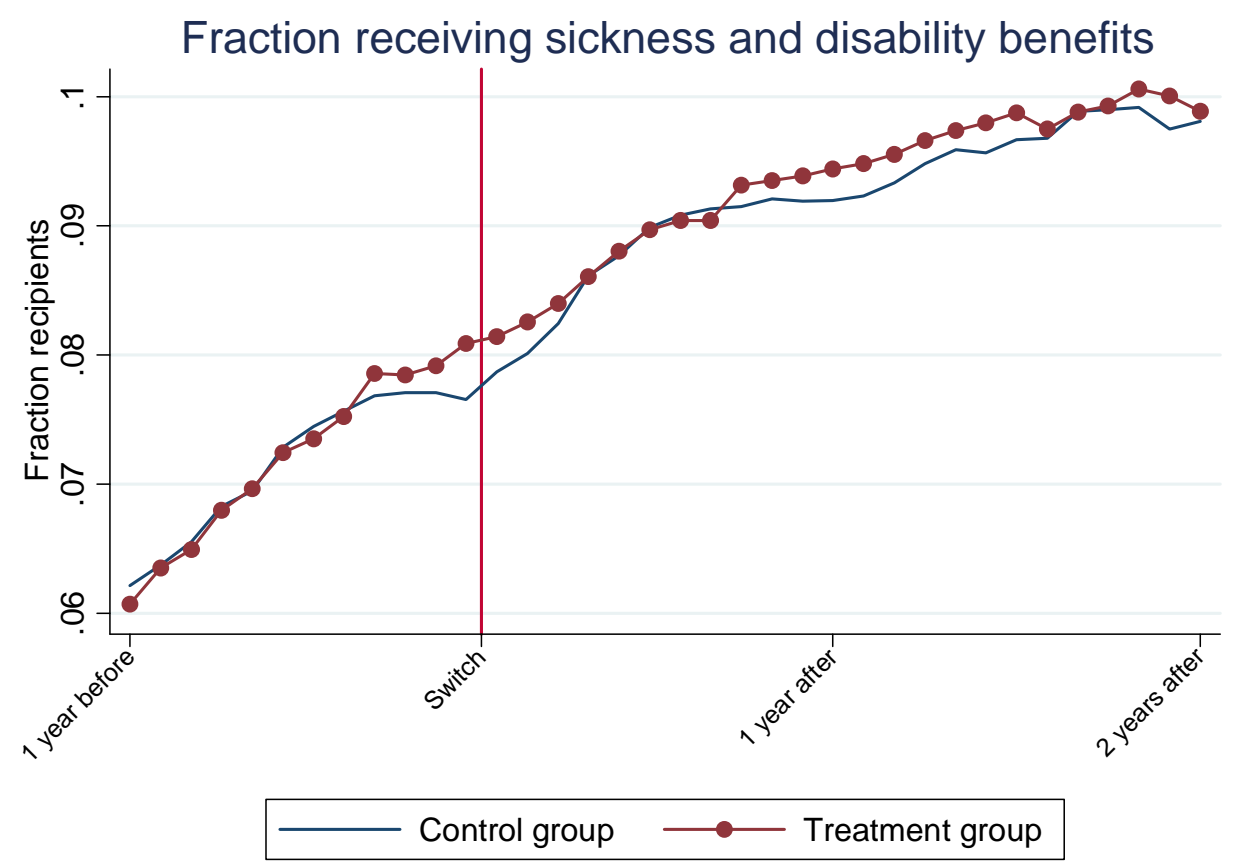

Figure 3. Sick pay and disability insurance claims before and after physician shift 
Figure 3 shows the fraction of the workers claiming sick pay or disability benefits in the treatment and control groups before and after the (genuine or placebo) shift. An apparently surprising pattern to note from this graph is the decline in sick pay and disability insurance claims observed for the control group around the time of the treatment groups' physician shifts (which, by construction, are irrelevant for the control groups). This arises, however, from the fact that a disproportionally large fraction of physician shifts occur in holiday periods (see Figure 1), implying that the seasonal pattern is correlated with the timing of the shifts (a similar pattern occurs one year later). It may also be noted that there is a positive trend in claim-propensities in both groups, primarily reflecting the initial condition of employment. A potentially more interesting pattern revealed by Figure 3 is that there seems to be a tendency of a slightly stronger rise in the treatment group than in the control group, starting some time before the shifts actually take place.

\section{Empirical analysis}

As a group of patients is exogenously moved from one GP to another, there are two types of effects we would expect. First, if the new GP has a different practice style than the old one, this may induce a shift in the group's overall benefit claim propensity. If new GP's on average are as strict as the old ones (which appears plausible), this will not change the average claim propensities in the effected groups as a whole some will be subject to a stricter GP and some to a more lenient GP - but the variation will increase. Second, all GP-client relationships will be subject to a potential non-familiarity effect of a priori unknown sign: A new GP-patient relationship may imply a more lenient GP if the new doctor is subject to stronger competitive pressures 
than more established ones, or if it takes time to notice patient-specific patterns indicative of shirking. It may imply a stricter GP if a settled GP-patient relationships introduces a familiarity/friendship that makes the GP more inclined to grant the patient's wishes.

Let $y_{i m t}$ be an indicator variable which is equal to 1 if individual $i$, belonging to group $m$, received a physician-certified benefit in month $t$, and zero otherwise. To identify the effects of interest, we formulate the linear probability model

$$
\begin{aligned}
y_{i m t} & =\alpha_{m}+\theta_{m, n} I(t \geq s) \\
& +\delta_{1} I(s-6<t<s)+\delta_{1}^{T} I(s-6<t<s) \times I(n \neq m) \\
& +\delta_{2} I(s<t<s+12)+\delta_{2}^{T} I(s<t<s+12) \times I(n \neq m) \\
& +X_{i t} \beta+\varepsilon_{i t} .
\end{aligned}
$$

Here, $\alpha_{m}$ is a patient-group fixed effect, $I($.$) is an indicator variable taking the value 1$ when the statement in the parenthesis is true, and $X_{i t}$ is a vector of control variables, which includes dummy variables for year and calendar month, as well as individual level patient characteristics (dummies for gender, age, education, and immigration status). The parameters of interest are the shift-specific effects $\left(\theta_{m, n}\right)$ for the genuine $(n \neq m)$ and «placebo» $(n=m)$ shifts respectively, and the parameters related to shiftanticipation and physician-familiarity $\left(\delta_{1}^{T}, \delta_{2}^{T}\right)$. Assuming that new physicians on average do not differ systematically from old physicians, the effects of non-familiarity are in this model captured by the average change in benefit claims from before to after the shift in the treatment group relative to the control group; i.e., $\underset{n \neq m}{E}\left(\theta_{m, n}\right)-\underset{n=m}{E}\left(\theta_{m, n}\right)$. After all, we follow patients no longer than two years after the shift of physician, and if the «newness» of the GP entails some distinct effects (beyond the characteristics of the physician), it seems likely that they are not washed out within two years. To the 
extent that the non-familiarity effect is stronger in the first year after the shift than in the second, this will be captured by the parameter $\delta_{2}^{T}$.

The test for the hypothesis that physicians have a real impact on sick pay and disability claims is that the variation in group-specific shift effects is larger in the treatment than in the control groups. When the new GP is more lenient than the old one, the frequency of benefit claims will rise, ceteris paribus; when the new GP is stricter than the old one, it will decline. In both cases, it will induce a change over and above what can be expected from random variation in the list-members behavior. In particular, we would expect there to be an element of «regression towards the mean»; i.e., that patient groups who used to have low insurance exploitation rates due to a very strict doctor before the shift tend to experience a rise in exploitation (since the new doctors in these cases on average will be more lenient than the old one) and vice versa.

Table 2 summarizes our main estimation results. We start out discussing the estimated shift effects reported in part II of the table. It follows from the discussion above that we are not interested in any particular of the 382 estimated shift parameters; rather it is the distribution of these parameters - for the treatment groups compared to the control groups - that is of interest. The main point to note from the results table is that the variation in the estimated shift effects is much larger for the treatment groups than for the control (placebo shift) groups. Both the standard deviation and the mean absolute difference is around $25 \%$ larger for the treatment groups than for the control groups. The difference is also highly statistically significant (pvalue $=0.002$ ). Thus, our results indicate that physicians do have a say over social insurance expenditures. 
A second point to note is that the rise in overall benefit use from before to after the shift is significantly larger in the treatment group than in the control group, suggesting that new doctors indeed find it more difficult to contain social security expenditures than more established doctors. There is no difference between the first and the second year after the switch, however, indicating that the non-familiarityeffects are roughly the same in these two years.

Table 2 Main results (standard errors in parentheses)

I. Estimated parameters

Period effects

The six months before switch

$0.08(0.07)$

First year after switch

$0.14(0.47)$

Period effects interacted with treatment

$\begin{array}{ll}\text { The six months before switch } & 0.15^{*}(0.09)\end{array}$

$\begin{array}{ll}\text { First year after switch } & -0.05(0.06)\end{array}$

II. Characterization of group/physician changes after genuine/placebo physician shift

Long-term change in control patient groups $(\mathrm{N}=191)$

Mean

$0.19 * *(0.09)$

Standard deviation

1.24

Mean absolute change

0.98

Long-term change in treated patient groups $(\mathrm{N}=191)$

Mean

$0.45 * * *(0.11)$

Standard deviation

1.55

Mean absolute change

1.24

Percentage difference in standard deviation between treatment group and control group

$25 \%$

Percentage difference in mean absolute change between treatment group and control group

$25 \%$

Test for difference in means (F-test)

$\mathrm{P}=0.0786 *$

Test for difference in standard deviations (F-test)

$\mathrm{P}=0.002 * * *$

Number of observations

4466160

Number of patients

124060

Number of physicians

382 


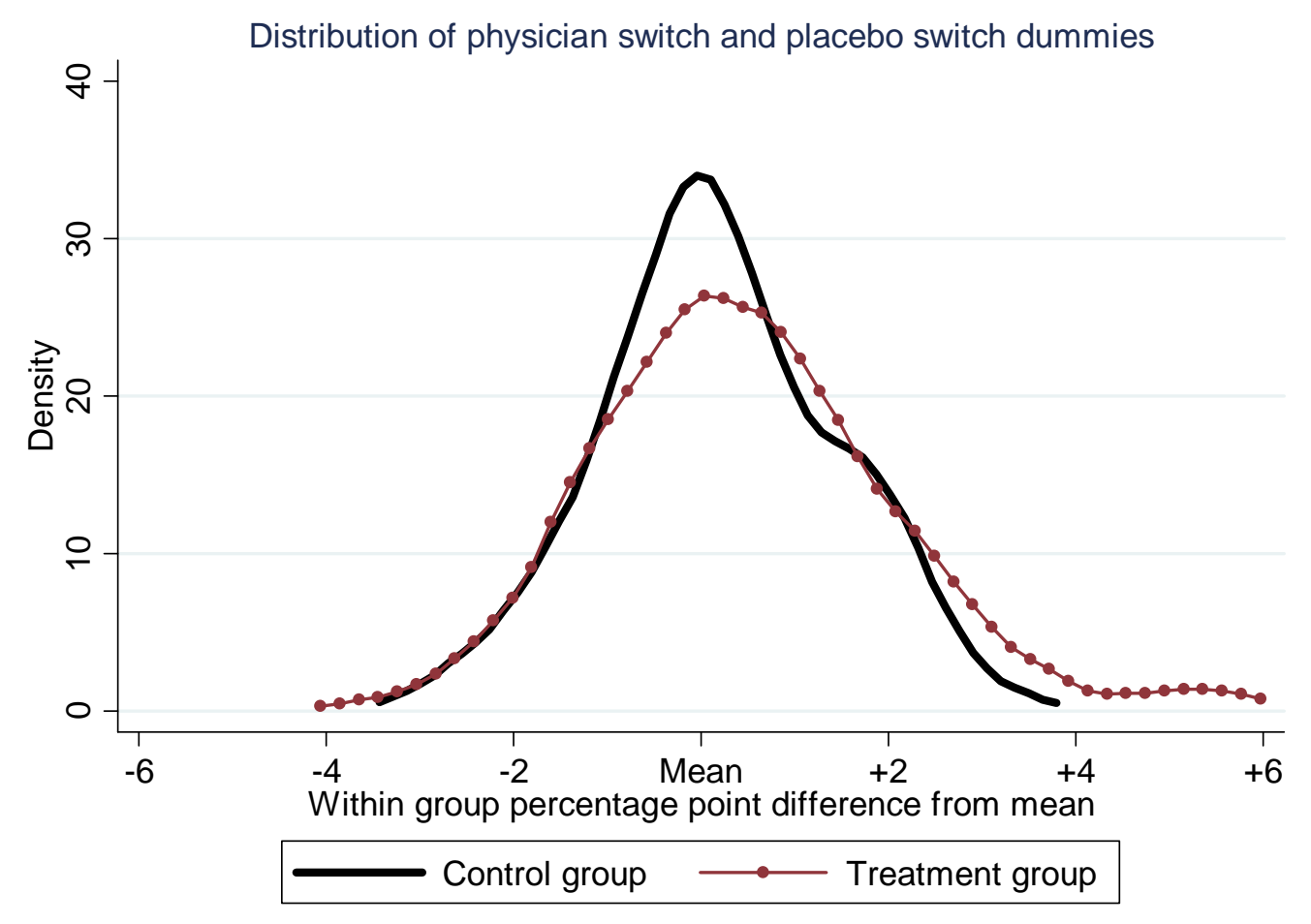

Figure 4 - Distributions of estimated «physician differences» $\left(\hat{\theta}_{m, n}\right)$

Figure 4 compares the distributions of estimated shift effects for the treatment and control groups. The two distributions clearly differ, and it is noticeable that the genuine shift-effects for the treatment groups have a wider (and more right-skewed) distribution than the placebo shift-effects in the control groups. Figure 5 plots the estimated shift-effects against the estimated group-fixed effects $\alpha_{m}$. Since the groupfixed effects contain a combination of the initial GP's strictness and uncontrolled-for patient sorting, we can use these plots to assess the regression-towards-the-meanhypothesis. Although the evidence is less than overwhelming, we do see a statistically significant tendency for regression towards the mean in the treated groups (in contrast to the control groups where the slope coefficient is insignificantly different from zero). 

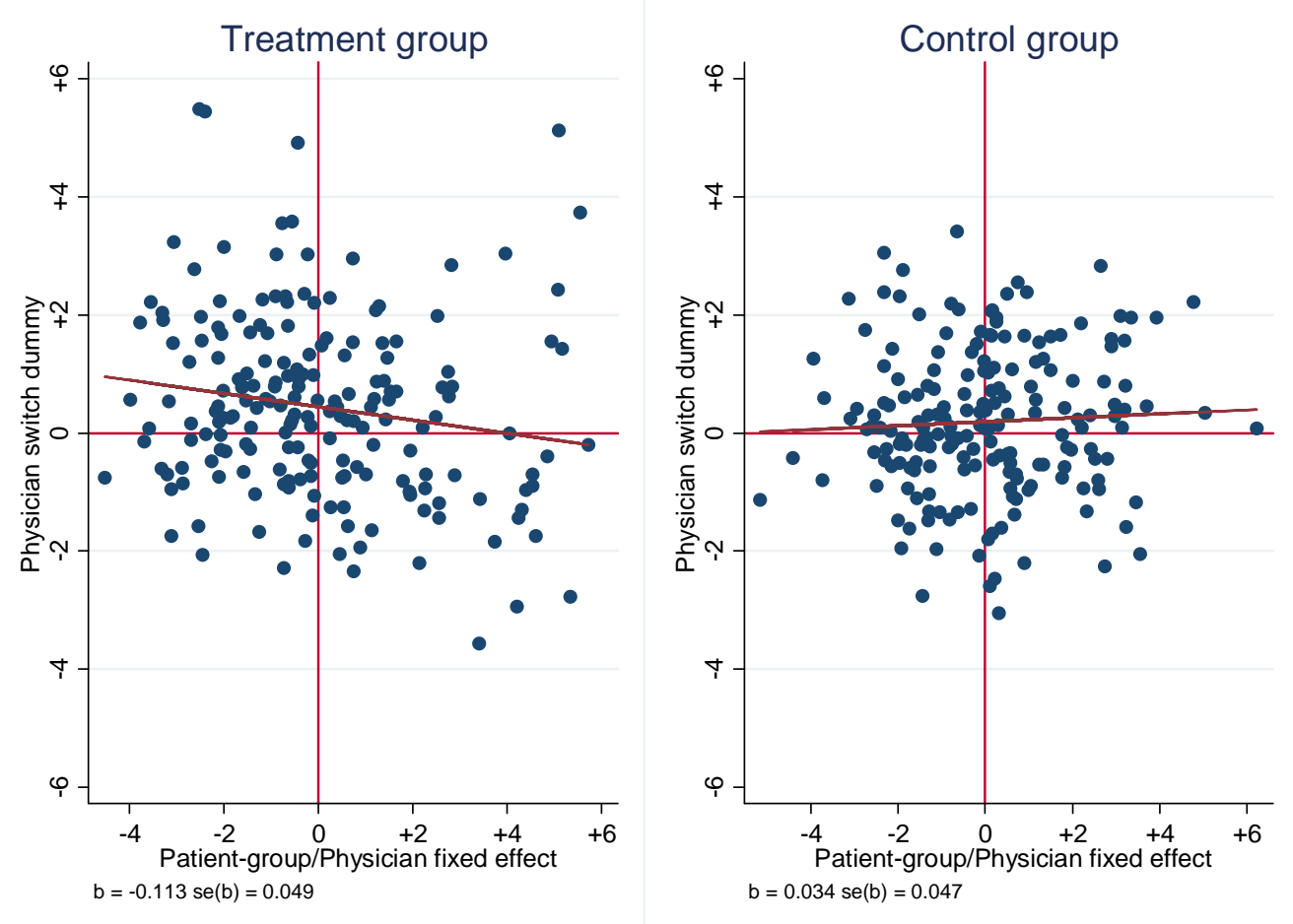

Figure 5. Cross-plot of estimated shift-effects against group-fixed effects

A final point to note is that there seems to be a shift-anticipation effect in the form of a rise in benefit claims the last six months of a GP's practice. This may result from a change in the GP's practice style and/or from the physician-shifts that actually occur during this period.

\section{Comparison with Previous Findings}

Markussen et al. (2011) computed physician-strictness indicators for all family doctors in Norway, based on their sickness absence certification propensity after controlling for the observed characteristics of all their employed clients. Even though they used a multivariate hazard rate model, the identification of physician-strictness was almost entirely based on the cross-sectional variation in absence-certification practic- 
es. In contrast, our identification strategy relies entirely on the longitudinal variation in certification practices as one physician replaces another one for a fixed group of individuals. It is thus of some interest to examine the degree of concordance between these two strategies for identifying essentially the same thing; namely the physicians’ strictness with respect to the certification of health related social insurance benefits. We would of course not expect a perfect correlation, not only because we have used different statistical approaches and identification strategies, but also because the method used in the present paper - though highly robust with respect to the existence of unobserved patient sorting - suffers from a significant attenuation problem. In addition, it should be noted that we have used different outcome measures; while Markussen et al. (2011) study absenteeism only, we also investigate certification of rehabilitation and disability benefits in the present paper.

Given our use of group-fixed effects, we can obviously not offer strictness indicators for each physician; we can only offer estimates for the differences in strictness between the pairs of patient-supplying and patient-receiving physicians. However, based on the set of strictness indicators computed for each physician in Markussen et al. (2011), it is possible to compute similar differences-indicators for exactly the same physician-pairs. We have thus accessed the estimated strictness-indicators computed in Markussen et al. (2011) for each of the physician-pairs also appearing in our own dataset (121 in total), and computed the differences between the two doctors involved in each switch.

A comparison between pair-wise differences-in-strictness estimates reported in the present paper and those obtained in Markussen et al. (2011) is presented in Figure 6. Panel a) shows a cross-plot of the two sets of estimators. There is obviously a 
strong positive correlation between these two estimators. The regression coefficient is 0.55, with standard error 0.08. Panel b) compares the two distributions of the pairwise differences-in-strictness estimates. Given the extremely different ways in which these estimators have been obtained, we find the two distributions remarkably similar.
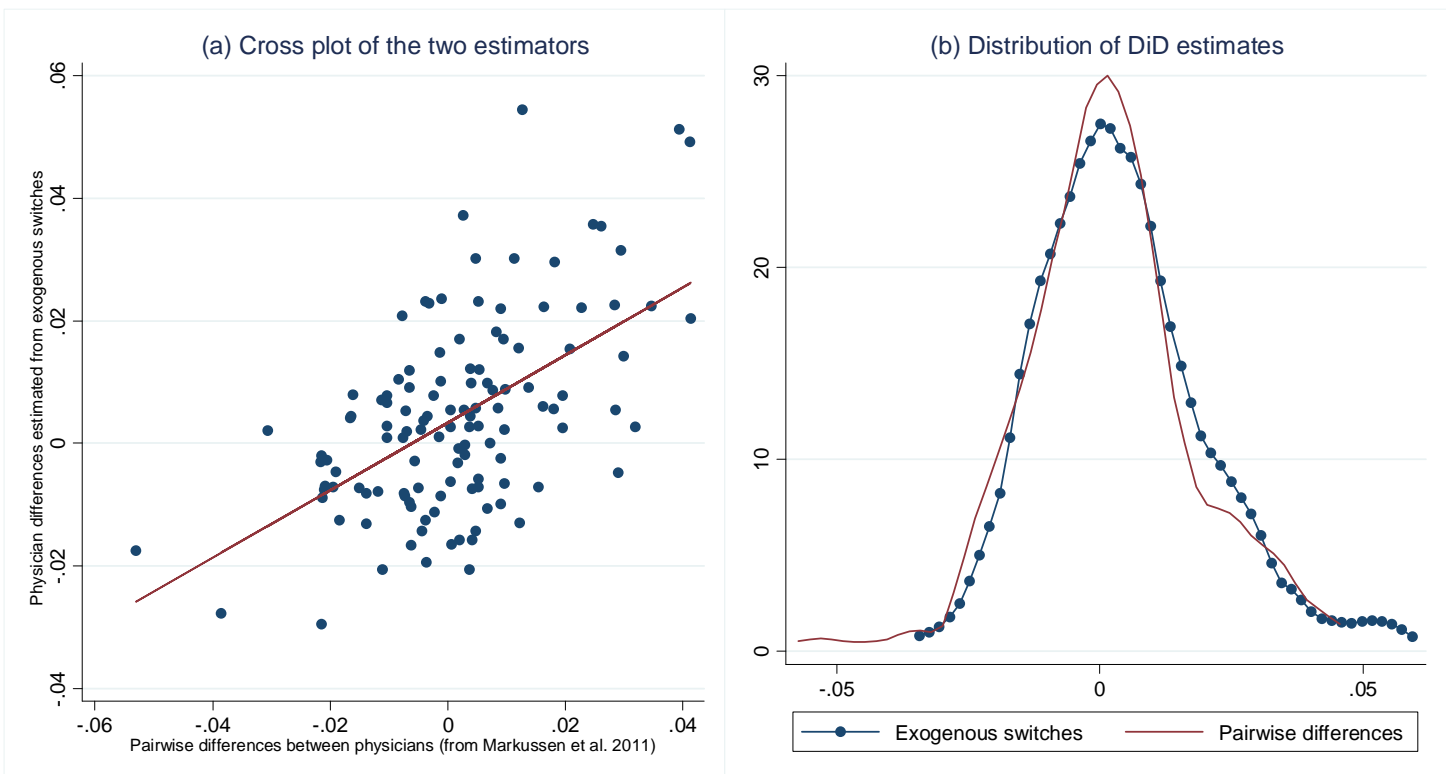

Figure 6. Comparison of pair-wise differences-in-strictness estimates reported in this paper with corresponding estimates computed from the results in Markussen et al. (2011)

\section{Conclusion}

General Practitioners are given a key role in many welfare states. They certify sick leaves, disability benefits, and prescription drugs, and refer patients to specialist treatment. Previous research has cast doubt on whether GPs are at all able to act as gatekeepers. This paper investigates whether GPs really differ in terms of their gatekeeper capabilities. We study this using Norwegian register data that makes it possible to examine groups of workers moving in bulk from one GP to another, switches that can be interpreted as exogenous changes of GP. 
We find that physicians really differ. The same people have substantially and significantly different sick pay and disability insurance propensities when connected to two different GPs. We take this as evidence for gatekeeping being possible since it shows that GPs really have a say. A second finding is that «new» physicians - who have not yet become familiar with their patients (and possibly not yet obtained a «settled» patient list) - are less strict gatekeepers.

The finding that family doctors have a significant impact on their clients' use of social insurance also suggest that the physicians' observed «practice styles» may constitute a potentially useful instrument for their clients' social insurance claims, making it possible to identify causal effects of such claims on, e.g., subsequent employment and earnings paths.

\section{References}

Blomqvist, Å., 1991. The doctor as double agent: Information asymmetry, health insurance, and medical care, Journal of Health Economics 10, 411-432.

Brekke, K. R., Nuscheler, R., Straume, O. R., 2007. Gatekeeping in health care, Journal of health economics, 26, 149-170.

Carlsen, N., Nyborg, K., 2009. The gate is open: Primary care physicians as social security gatekeepers. Memorandum 07/2009. Oslo: Department of Economics, University of Oslo.

Duggan, M., 2005. Do New Prescription Drugs Pay for Themselves? The Case of Second-Generation Antipsychotics. Journal of Health Economics, Vol. 24, 131. 
Dusheiko, M., Gravelle, H., Jacobs, R., Smith, P., 2006. The effect of financial incentives on gatekeeping doctors: Evidence from a natural experiment, Journal of Health Economics, Vol. 25, 449-478.

French, E. and Song, J., 2009. The Effect of Disability Insurance Receipt on Labor Supply. Working Paper, Federal reserve Bank of Chicago.

Grytten, J. and Sørensen, R., 2003. Practice Variation and Physician-Specific Effects. Journal of Health Economics, Vol. 22, 403-418.

Maestas, N., Mullen, K. and Strand, A., 2011. Does Disability Insurance Receipt Discourage Work? Using Examiner Assignments to Estimate Causal Effects of SSDI Receipt. Rand Working Paper, WR-853-2,

Markussen, S., 2012: The effects of sick-leaves on earnings, Journal of Population Economics, Vol. 25(4), 1287-1306

Markussen, S., Røed, K., Røgeberg, O.J., Gaure, S., 2011. The anatomy of absenteeism. Journal of Health Economics, Vol. 30 (2011), No. 2, 277-292.

OECD, 2010. Sickness, Disability and Work: Breaking the Barriers - Key Trends and Outcomes in Sickness and Disability. OECD, Paris

Scott, A., 2000. Economics of General Practice, Handbook of Health Economics, Volume 1, Chapter 22, Elsevier science.

Stone, D., 1984. The Disabled State, Temple University Press, Philadelphia

Wilkin, D., 1992. Patterns of referral: Explaining variation, in: M. Roland and A. Coulter, eds., Hospital Referrals, Oxford General Practice Series 22, Oxford University press.

Wooldridge, J., 2002. Econometric analysis of cross section and panel data, 